\title{
A ousadia da resistência: A luta dos trabalhadores da Ford contra 2800 demissões
}

The Boldness of Resistance: The Struggle of Ford Workers against 2,800

Dismissals

L'audace de la résistance: La lutte des travailleurs de Ford contre 2800

licenciements

Roberto Véras

\section{(2) OpenEdition}

\section{Journals}

Edição electrónica

URL: http://journals.openedition.org/rccs/1326

DOI: $10.4000 /$ rccs. 1326

ISSN: 2182-7435

\section{Editora}

Centro de Estudos Sociais da Universidade de Coimbra

Edição impressa

Data de publição: 1 Junho 2002

Paginação: 97-120

ISSN: 0254-1106

Refêrencia eletrónica

Roberto Véras, "A ousadia da resistência: A luta dos trabalhadores da Ford contra 2800 demissões », Revista Crítica de Ciências Sociais [Online], 62 | 2002, colocado online no dia 01 outubro 2012, criado a 30 abril 2019. URL : http://journals.openedition.org/rccs/1326 ; DOI : 10.4000/rccs.1326 


\section{ROBERTO VÉRAS}

Escola Sindical São Paulo da CUT e Centro de Estudos dos Direitos da Cidadania/USP

\section{A ousadia da resistência: A luta dos trabalhadores da Ford contra 2800 demissões ${ }^{1}$}

Analisa-se o movimento dos trabalhadores da Ford de São Bernardo, em São Paulo, contra o anúncio, pela empresa, de 2800 demissões em Dezembro de 1998. Discutem-se, sem pretensões conclusivas, as condições e possibilidades de resistência oferecidas pelo sindicalismo CUT aos processos ora em curso no Brasil, que apontam, como tendências principais, para a flexibilização de direitos, a precarização das relações de trabalho, a destituição dos sujeitos colectivos que se colocam numa perspectiva autónoma e, por conseqüência, a desarticulação do espaço público.

\section{Introdução}

Ao longo dos anos 90, o Brasil sofreu importantes mudanças em sua base econômica e em suas dinâmicas social e política. $\mathrm{Na}$ década anterior, a partir de um longo processo de "transição conservadora" (O'Donnell, 1988), um persistente quadro de estagnação econômica e instabilidade monetária e intensos conflitos sociais, constituíram-se novos sujeitos coletivos, na forma de movimentos sociais e sindicais. Ao trazerem para o debate público "questões e temas antes silenciados ou considerados como não pertinentes para a deliberação política", tais sujeitos atuaram no sentido da ampliação do campo da política, ressignificando noções como "direitos" e "cidadania". O marco na promessa de uma nova institucionalidade no país foi a promulgação da Constituição de 1988, que, apesar de importantes limites e ambivalências, incorporou novos direitos sociais e instrumentos legais e jurídicos inéditos de garantia da cidadania (Paoli e Telles, 2000: 101-109).

${ }^{1} \mathrm{O}$ presente paper é uma versão modificada de um trabalho apresentado ao XXIV Encontro Anual da Associação Nacional de Pós-Graduação e Pesquisa em Ciências Sociais, realizado entre 23 e 27 de outubro de 2000, em Petrópolis, Rio de Janeiro. 
O processo político brasileiro, no entanto, estava na contramão das tendências internacionais. O “ajuste” não tardou, porém. Os governos Collor e Cardoso, em especial, encarregaram-se de reorientar sua inserção na nova dinâmica internacional (Fiori, 1997). As políticas de orientação neoliberal, que passaram a ser intensivamente adotadas, operaram mudanças para além de seu sentido meramente econômico, como se quer deixar transparecer. Para Oliveira seu sentido último é o da "privatização do público" ${ }^{2}$. Com isso, coloca-se em rota de colisão com as conquistas sociais e políticas da década anterior. Daí a necessidade de processar-se uma Reforma do Estado e uma Revisão Constitucional, tarefas que tais governos perseguiram persistentemente no último período.

Tal situação repercutiu de modo contundente no campo da ação sindical. Primeiro, o sindicalismo - a Central Única dos Trabalhadores (CUT) em destaque - esteve entre os principais protagonistas das lutas trabalhistas, sociais e políticas, que resultaram nas conquistas expressas no novo texto constitucional. Segundo, a abrupta abertura comercial e os processos de privatização, desnacionalização e reestruturação, pelos quais vem passando a economia brasileira, contribuíram decisivamente para elevar o patamar de desemprego e precarizar as relações de trabalho. Terceiro, ao se colocar como o principal fator de resistência à flexibilização de direitos, à precarização do trabalho e ao processo de destituição dos sujeitos coletivos autonomamente constituídos, tornou-se um "obstáculo" a ser removido. ${ }^{3}$

Colocado em uma condição essencialmente defensiva, o sindicalismo CUT esboça reações pontuais. Que possibilidades se coloca, na resistência ao desmanche ${ }^{4}$, de modo a revertê-lo? Ou seja, em que medida sinaliza,

\footnotetext{
2 "A privatização do público é uma falsa consciência de desnecessidade do público. Ela se objetiva pela chamada falência do Estado, pelo mecanismo da dívida pública interna, onde as formas aparentes são as de que o privado, as burguesias, empresam ao Estado: logo, o Estado, nessa aparência, somente se sustenta como uma extensão do privado. O processo real é o inverso: a riqueza pública, em forma de fundo, sustenta a reprodutibilidade do valor da riqueza, do capital privado" (1999: 68).

${ }^{3}$ Zapata (1994) propõe uma síntese dos principais impactos sofridos pelo sindicalismo da América Latina, com a transição de um modelo de desenvolvimento baseado, grosso modo, na industrialização por substituição de importações para um outro apoiado na transnacionalização do mercado interno. Destaca: a abertura ao mercado internacional, as mudanças na estrutura ocupacional, a privatização das empresas estatais e a ofensiva anti-sindical. Para Oliveira (1998: 214), entretanto, "há algo mais tenebroso por trás da renúncia ao combate ao desemprego e à miséria": "as classes dominantes na América latina desistiram de integrar a população, seja à produção, seja à cidadania”. A própria possibilidade da democracia estaria, assim, em questão.

${ }^{4}$ Expressão adotada pelo Centro de Estudos dos Direitos da Cidadania - Cenedic/USP, com o intuito de designar as iniciativas de cunho neoliberal, ora em curso, voltadas a flexibilizar direitos e destituir o espaço público.
} 
com suas ações, uma contratendência à "privatização do público", empreendendo a "publicização do debate e do dissenso" (Paoli, 1999), a reafirmação da necessidade do público ${ }^{5}$ ?

Sem a pretensão de apresentar uma abordagem de caráter mais conclusivo a esse respeito, nos propomos analisar a luta dos trabalhadores da Ford de São Bernardo do Campo (São Paulo), contra a tentativa da empresa de promover 2800 demissões, em dezembro de 1998. Buscamos nessas experiência sinais das possibilidades acima referidas.

\section{Dos anos 80 aos 90: novo cenário para a ação sindical}

As greves metalúrgicas ocorridas em São Paulo, particularmente no $\mathrm{ABC}^{6}$, entre 1978 e 1980, constituíram um novo marco na história do sindicalismo brasileiro. Seus impactos logo se fizeram sentir no projeto de auto-reforma do regime militar, denominado sucessivamente de "distensão" e de "abertura”. Uma nova prática sindical surgia lutando, no campo sindical, pela liberdade e autonomia sindical, pelo direito de organização dos trabalhadores no local de trabalho e pelo direito de greve; e, no campo político, pela democratização da sociedade brasileira, nas suas dimensões política, social e econômica.

O "novo sindicalismo" não só destoava do que se permitia como ação sindical nos anos mais duros da ditadura, engessada que estava pelo controle propiciado pela estrutura sindical corporativista ${ }^{7}$ e pelo papel essencialmente assistencialista que estava obrigado a cumprir. Também procurava diferenciar-se do sindicalismo praticado no período que precedeu ao Golpe Militar de 1964, que no jargão acadêmico e político fora genericamente denominado de populista ${ }^{8}$. O "novo sindicalismo" surgiu da ação sindical voltada ao interior das empresas, declarou-se autônomo perante o Estado e os partidos políticos, colocou-se no cenário público do país como um sujeito político independente.

\footnotetext{
${ }^{5}$ Este termo é aqui usado no sentido arendtiano, como espaço da visibilidade pública, da "aparência", onde a ação e o discurso de cada um podem adquirir um sentido de constituição de um "mundo comum", auto-reconhecendo-se como compartilhando um destino comum, regido portanto pela pluralidade humana: "O mundo comum acaba quando é visto somente sob um aspecto e só se lhe permite uma perspectiva” (Arendt, 1999: 68).

${ }^{6}$ Região que integra a área metropolitana da Capital e é formada por 7 municípios, cujos mais importantes são: Santo André, São Bernardo e São Caetano. De suas iniciais derivou a denominação "ABC".

7 Que havia sido implantada no Estado Novo, entre as décadas de 30 e 40. Nos termos de Schmitter (1974), caracterizar-se-ia como um corporativismo de tipo estatal.

${ }^{8}$ Segundo Weffort (1973), tratou-se de uma prática sindical prevalecente sobretudo a partir dos anos 50 até o Golpe e caracterizou-se, grosso modo, por acomodar-se à estrutura corporativista e manter-se estreitamente ligada ao regime populista e à ideologia nacionalista.
} 
Mas, ao contrário de outras experiências internacionais de superação de sistemas sindicais corporativistas ${ }^{9}$, no Brasil o projeto de ruptura articulou-se, desde o início, por dentro do próprio sindicato oficial. A CUT, no seu momento de fundação, em 1983, confirmou tal estratégia, elegendo a conquistar de sindicatos, através de "oposições sindicais" como prioridade, de modo a poder democratizá-los, enraizá-los nas bases e os articular sob uma perspectiva classista.

Ao longo dos anos 80, a CUT afirmou-se como a principal central sindical do país, ${ }^{10}$ conquistou a maioria dos principais sindicatos, posicionou-se contra os acenos do governo com vistas a um pacto social, conduziu (com apoio da CGT) três greves gerais (1986, 1987 e 1989), atuou com destaque, sempre como oposição, no debate político da "transição". A nova Constituição, promulgada em 1988, recebeu os protestos da CUT, por suas insuficiências, apesar do reconhecimento de certos avanços. A década foi concluída com a eleição presidencial, diante da qual a Central posicionou-se em favor da candidatura de Luis Ignácio Lula da Silva, principal líder das lutas históricas de 1978-80.

Nos anos 90, sobretudo com os governos Collor e Cardoso, o Brasil operou a passagem de um modelo de desenvolvimento genericamente denominado de "substituição de importações", centrado em um papel ativo do Estado, para um modelo de liberalização comercial e financeira, orientado para uma inserção internacional subalterna, com repercussões importantes no papel do Estado. ${ }^{11}$

Para Pochmann et al. (1998), constituía-se a partir dali um novo cenário para ação sindical no país: o desemprego crescente, decorrente de políticas recessivas, da desregulação e redução do papel do Estado, da abertura comercial abrupta, da elevação das taxas de juros e da valorização cambial; o fim da indexação salarial - eixo da mobilização sindical na década de 80; a modernização dos segmentos de ponta da economia, acompanhada da desestruturação e desnacionalização de vários outros; a mudança radical na composição setorial do emprego em favor do setor de serviços etc.

\footnotetext{
9 Particularmente, os casos da Itália do pós-guerra, da Espanha pós-franquista e de Portugal póssalazarista.

${ }_{10}$ Ao lado da CUT, as mais importantes são a Central Geral dos Trabalhadores - CGT, criada em 1986, e a Força Sindical, crida em 1991.

${ }^{11}$ Esse papel, nos termos de Fiori (1997: 237), reduziu-se, na prática, "à função exclusiva de guardião dos equilíbrios macroeconômicos. Guardiães que acabam prisioneiros de sua própria armadilha e impotentes, ou incapazes, de definir prioridades e implementar políticas de incentivo setorial à competitividade, de oferecer proteção social às suas populações, de prestar os serviços públicos mais elementares, ou mesmo finalmente de garantir a ordem e o respeito às leis".
} 
Mas, aos novos desafios trazidos por tais mudanças, acrescentam-se os antigos, particularmente no que se refere à persistência do modelo sindical corporativista e à tendência progressiva de acomodação nela dos diversos segmentos sindicais, incluindo da CUT (Boito Jr., 1991). Considere-se, por outro lado, que tal instituição passa também a ser um obstáculo segundo a perspectiva neoliberal. O debate sobre a sua eliminação ressurge como parte de uma tendência mundial de desregulamentação dos direitos sociais e de flexibilização das relações de trabalho, ${ }^{12}$ particularmente em um momento de fragilização do sindicalismo. As iniciativas governamentais na área visam, de um lado, eliminar a regulamentação e a ação do Estado no âmbito do direito individual do trabalho e, por outro, restringir o poder sindical, quanto à negociação coletiva e ao direito de greve. O governo tem feito a opção de promover tais mudanças através de iniciativas pontuais, tais como: Medida Provisória sobre a Participação nos Lucros e Resultados (PLR), em 1994; decretação do fim da indexação salarial, em 1995; lei das cooperativas de trabalho, em 1994; lei da contratação por tempo determinado, em 1998; e diversas ameaças de eliminação do monopólio da representação e do imposto sindical (Krein e Oliveira, 1999). ${ }^{13}$

Para Oliveira (1998), o sindicalismo ligado à CUT tornou-se um dos alvos prioritários das políticas neoliberais, com as quais o atual governo encontra-se profundamente identificado. ${ }^{14} \mathrm{~A}$ posição intransigente com que o Governo Cardoso, no início do seu primeiro mandato, em 1995, tratou a greve dos petroleiros, dirigida pela Federação Única dos Petroleiros, filiada à CUT, teria sido um exemplo. Um profundo movimento de ressignificação estaria sendo operado na sociedade ("a burguesia já não trata de integrar os dominados ao seu próprio campo de significados”), concorrendo para aprofundar o sentido de exclusão social. Os direitos sociais são tomados, no seu sentido inverso, como "obstáculos ao desenvolvimento econômico, e mais, são transformados em fatores causais da miséria, pobreza, exclusão e ausência de cidadania"; são identificados como "privilégios". Ao mesmo tempo, o direito da contestação é não só reprimido, "ele é desqualificado como direito" (Oliveira, 1998: 216).

12 Quanto ao debate atual sobre as mudanças no Direito do trabalho, ver Siqueira Neto (1996) e Krein e Oliveira (1999), sobre o Brasil, e Zapata (1994) e Uriarte (1995, 1996), sobre a América Latina.

13 Atualmente tramita no Congresso um projeto de reforma da Consolidação das Leis Trabalhistas - CLT, que torna alguns direitos legalmente constituídos em objeto de negociação coletiva. O que, na prática, significa converter o que era piso em teto.

${ }_{14}$ A respeito do caráter neoliberal do governo Fernando Henrique Cardoso (FHC), ver também Fiori (1997). 
O sindicalismo, inclusive cutista, assume com isso uma posição fundamentalmente defensiva. Mas, ao mesmo tempo cria novas oportunidades e ensaia novas práticas sindicais. No que se refere à ação sindical frente aos processos de reestruturação produtiva, ganhou destaque a experiência da "reestruturação negociada" conduzida pelos metalúrgicos do $\mathrm{ABC}$ junto às empresas da região (Blass, 2001). O marco dessa nova fase foi, no entanto, a experiência, de vida curta, das Câmaras Setoriais ${ }^{15}$.

As oportunidades de renovação da prática sindical, de modo geral, relacionaram-se ao surgimento de novos espaços institucionais, nos quais as entidades sindicais vêm tendo uma participação crescente e, com isso, assumindo compromissos com a elaboração, fiscalização e até execução (pontualmente) de políticas públicas, especialmente da área social. Tendo sido possibilitados pela Constituição de 1988, esses espaços vêm sendo efetivados principalmente a partir do início dos anos 90. Segundo Pochmann et al. (1998: 15), em "sua maioria, são não paritários, deliberativos, têm como objetivo a formulação de diretrizes e foram criados a partir de decisões do Poder Executivo...”. Ganharam maior destaque na agenda sindical: o Conselho Deliberativo do Fundo de Amparo ao Trabalhador (Codefat) e as Comissões Estaduais e Municipais de Emprego e Trabalho; os conselhos de saúde e de educação, nas várias esferas de governo, entre outros.

Acrescente-se a isso, como fatores de diversificação da ação sindical, o seu envolvimento em espaços sindicais e internacionais internacionais, notadamente a partir da constituição, em 1991, do Mercosul ${ }^{16}$, da filiação da CUT, em 1992, à Confederação Internacional das Organizações Sindicais Livres (Ciosl) e da reação sindical continental à criação da Alca (Acordo de Livre Comércio das Américas ).

A prática sindical cutista, nos anos 90 , ao mesmo tempo em que perde poder de mobilização, assume uma nova agenda, onde a questão do emprego, na proporção em que cresce o desemprego e avança a precarização do trabalho, vem assumindo cada vez mais um lugar central. Ganham tam-

\footnotetext{
${ }^{15}$ Constituídas como espaços públicos de negociação tripartite, envolvendo o governo, empresários e sindicatos, envolveram vários setores da economia (metalúrgico, máquinas agrícolas, químico, construção civil), entre 1992 e 1993. Foram desativadas quando FHC tornou-se Ministro da Fazenda e, depois, Presidente da República. O caso de maior destaque foi o do Setor Automotivo, que realizou dois acordos, avaliados por Oliveira et al. (1993: 6) como um ponto de inflexão no padrão de relações de trabalho no país, ao inaugurar uma "nova contratualidade". Ver ainda: Oliveira et al. (1992), Arbix (1996), Cardoso e Comin (1995).

${ }^{16}$ Ver, por exemplo, Castro (2000) e Melo (2001). Hermes Costa (CES/Universidade de Coimbra) atualmente desenvolve estudo sobre esse tema.
} 
bém destaque iniciativas relacionadas com temáticas como formação profissional, saúde, educação, transporte, habitação, previdência, cidadania. É quando se fala em “sindicato cidadão" (Véras, 2002a).

\section{Notas sobre a indústria automobilística no Brasil}

A indústria automobilística teve seu primeiro grande impulso no país nos anos 50, concentrando-se inicialmente no Estado de São Paulo, na Região do ABC. ${ }^{17}$ Além da GM, Ford e FNM (Fábrica Nacional de Motores), acrescentaram-se, nesse período, unidades da VW, Simca, Willys, Mercedes-Benz, Scania e Toyota. Nos anos 70, durante o "milagre brasileiro", o setor alcançou uma produção recorde de 1 milhão de unidades. Iniciava-se ali um movimento de descentralização do setor, com a instalação de novas fábricas em Minas Gerais (Fiat); no interior de São Paulo (VW, Ford, GM e Mercedez-Benz); no Paraná (Volvo). A participação do $\mathrm{ABC}$ na produção nacional de veículos passou de 75\%, em 1975, para 56\%, em 1980. Com a recessão do começo dos anos 80, os níveis de produção caíram, só recuperando-se em 1986 e permanecendo estável até 1992. Só então, com os acordos firmados no âmbito da Câmara Setorial Automotiva, o setor registrou um novo surto de crescimento. De 1992 a 1997, a produção cresceu até atingir os 2 milhões de veículos (atingindo o $10{ }^{\circ}$ lugar no ranking mundial). ${ }^{18}$ Nos anos seguintes a produção voltou a cair, chegando a 1,2 milhões, em 1999.

A elevação na capacidade produtiva do setor foi acompanhada de mudanças no padrão produtivo, iniciadas nos anos 80 , mas só intensificadas na década seguinte, com a introdução de novas técnicas de gestão da produção e do trabalho (terceirização, "just-in-time”, "kaban”, "kaizen”, células de produção, trabalho em grupo, polivalência, redução dos níveis hierárquicos). A produtividade do setor passou, então, de um patamar de 8 unidades/trabalhador, até 1992, para algo em torno de 18, em 1996. Entretanto, resultaram daí sistemáticas perdas de postos de trabalho e um franco processo de precarização dos contratos de trabalho. O número de empregados nas montadoras manteve-se, durante os anos 90, em torno de 100 mil, mesmo com a expansão ocorrida (em meados da década de 80 havia chegado a 130 mil). Nos últimos anos esse nível vem caindo, tendo chegado

\footnotetext{
17 Ver, por exemplo, SMABC (1996), Castro (1995), Arbix e Zilbovicius (1997) e CNM/Dieese (1998).

${ }^{18}$ Houve, também, uma alteração na composição do produto: a participação dos chamados "carros populares”, lançados em 1993, passou de $23,7 \%$ para $61,4 \%$ da produção total, em 1997, demarcando uma especialização frente à produção mundial (CNM/Dieese, 1998: 71).
} 
em 1999 a 84 mil trabalhadores. O segmento de autopeças, com o acentuado processo de concentração e desnacionalização sofrido, foi um dos que mais danos trouxe aos trabalhadores. ${ }^{19}$

O desempenho da indústria automobilística na segunda metade da década de 90 esteve diretamente relacionado ao advento da "guerra fiscal". O governo federal, em 1995, estabeleceu um "novo regime automotriz", criando uma série de incentivos fiscais ${ }^{20}$ para atrair novos investimentos ao país. Desencadeou-se com isso uma acirrada disputa envolvendo governos estaduais e municipais, que passaram a oferecer vantagens tributárias, creditícias e de infra-estrutura às empresas interessadas em instalarem-se em seus territórios. Daí resultou um novo surto de expansão e descentralização do setor, com novas fábricas inauguradas: VW no Rio de Janeiro, em 1996, e no interior de São Paulo, em 1997; Renault, Chrysler e Audi/VW, no Paraná, em 1998; Mercedes-Benz, em Minas Gerais, em 1998; GM, no Rio Grande do Sul, em 2000; Ford, na Bahia).

Quanto à Ford, em particular, no final de 1998, quando anunciou 2800 demissões, havia iniciado um processo de desativação de sua unidade na cidade de São Paulo (fábrica de caminhões), mantinha a fábrica de motores em Taubaté (interior de São Paulo) e, além de deixar em aberto o futuro da unidade de São Bernardo do Campo (que produzia os modelos Fiesta e Ká), estava transferindo um projeto de nova planta do Rio Grande do Sul para a Bahia, na esteira da "guerra fiscal" ${ }^{21} \mathrm{O}$ cenário da luta de resistência dos trabalhadores da Ford às demissões assim se armara.

\section{Luiza e o sindicalismo do ABC}

Luiza ${ }^{22}$ é casada com um dos demitidos pela Ford em dezembro de 1998. Embora sindicalizado, ele sempre se comportou de modo disciplinado em relação ao trabalho, nunca se envolveu em lutas sindicais. Ela há muito não tem um emprego, faz bicos para ajudar no orçamento doméstico. No dia 23 de dezembro receberam uma carta da empresa anunciando a demissão. Ao procurarem o Sindicato, deram-se conta da dimensão do problema. A orientação recebida foi a de não assinar a rescisão do contrato e de comparecer a uma assembléia convocada para o dia 4 de janeiro, na porta da fábrica, na volta do recesso. O Sindicato convoca os trabalhadores para resistirem às

\footnotetext{
${ }_{19}$ Nesse segmento, o nível de emprego caiu de mais de 300 mil trabalhadores, em 1989, para pouco mais de 230 mil, em 1994 (SMABC, 1994).

${ }^{20}$ Sobretudo reduzindo a alíquota de importação de peças, de componentes e de máquinas.

${ }^{21}$ A respeito dos custos público da "guerra fiscal", particularmente no que se refere à indústria automobilística, em estudo comparado com o caso norte-americano, ver Arbix (2001).

${ }^{22}$ Nome fictício.
} 
demissões. Luiza também não queria aceitar aquela situação e resolveu estimular outras esposas de demitidos a participarem, com seus maridos, da assembléia marcada.

Ela não havia participado do debate sobre as mudanças que estavam se processando nas empresas, na indústria automobilística, na sociedade. Não conhecia o Sindicato, não compartilhava da experiência sindical que vinha sendo construída no $\mathrm{ABC}$ há mais de duas décadas ${ }^{23}$. Mas não queria aceitar aquela situação e viu no Sindicato uma possibilidade de resistência. Foi na assembléia do dia 4. Muita gente reunida, as lideranças falando, as pessoas se manifestando, tudo era uma grande novidade. Mas estava atenta:

Eu lembro quando o Vicentinho ${ }^{24}$ olhou e falou assim: "aqui tá o retrato de uma família desempregada, esposa, marido e o filho". Naquele momento, eu não esperava que ninguém fosse me ver ali. Mas, eu esperava ouvir alguma coisa de alguém. Eu lembro que o Marinho ${ }^{25}$ falou que ia ser uma luta muito difícil, muito árdua, muito dura, mas que era pra gente resistir, que a gente ia conseguir alguma coisa (...) Logo depois terminou a assembléia, aí choveu de jornalistas em cima de mim, do meu filho, do meu marido ${ }^{26}$

Em pouco tempo, ela se vê ao lado das lideranças sindicais e na mídia, se vê inserida em uma experiência com a qual não havia ainda compartilhado valores, idéias, atitudes. No turbilhão dos acontecimentos, foi construindo uma outra visão a respeito de tudo aquilo. Transitou rapidamente do alheamento e estranhamento à confiança de que algo poderia ser feito:

naquele dia (4 de janeiro), eu saí de lá confiante de que pudesse acontecer alguma coisa, se a gente fizesse também alguma coisa. Porque eu acho que a gente não pode ficar de braços cruzados, esperando. A gente tem que lutar, correr atrás.

Tornou-se parte do movimento: "a partir daquele instante, eu não queria perder mais nada”. Na primeira vez que pediu a palavra em uma reunião, estava convicta: "nós temos direitos; e isso é um direito... é direito humano; o que a gente deve fazer é lutar pelo emprego da gente". Passou a partici-

\footnotetext{
23 As famosas greves dos metalúrgicos do ABC eclodiram nos anos de 1978 a 1980, ainda sob a Ditadura Militar, desencadeando uma nova fase no sindicalismo brasileiro, denominado "novo sindicalismo".

${ }^{24}$ Vicente Paulo da Silva, então presidente da CUT e ex-presidente do Sindicato dos Metalúrgicos do ABC - SMABC.

${ }^{25}$ Luis Marinho é o atual presidente do SMABC.

${ }^{26}$ Depoimento dado ao autor em dezembro de 1999.
} 
par ativamente dos acontecimentos e trouxe para si a responsabilidade de mobilizar outras pessoas. Algo de novo lhe acontecia, novas pessoas, situações e idéias. À sua maneira, vai se inserindo naqueles acontecimentos (desencadeados com a decisão da Ford), naquele movimento (articulado pelo Sindicato e trabalhadores da empresa), naquela experiência (construída historicamente como um campo de referências), ao não aceitar a decisão da Ford, ao determinar-se a "fazer alguma coisa", ao descobrir o Sindicato e suas lideranças e ao redescobrir os colegas de trabalho do marido e suas esposas, agora como companbeiros. Então, reconhece: "Com certeza, eu mudei (...) Hoje, eu sou mais mulher... Porque eu não me conhecia como mulher (...) Eu, agora, procuro sempre tá fazendo alguma coisa”. Luiza torna-se parte (à sua maneira) daquela experiência.

É desse campo de experiência que pretendemos tratar aqui. Nos interessa identificar as possibilidades que lhes estão colocadas e que esse se coloca, a partir das escolhas que vem fazendo e das situações que vem criando, diante de novas realidades. Iniciamos o percurso centrando-nos em um acontecimento atual, relevante pela repercussão alcançada na mídia nacional, e que, em relação à referida experiência, a ela pertence (porque nela se inscreveu, dela derivou em alguma medida) e contém (porque sobre ela deixou uma marca, que como outras ajudou a delimitar novos contornos, em um percurso que se continua e se reinventa permanentemente). Escolhemos, ainda, iniciar a abordagem a partir de um olhar singular, o de Luiza, que construiu nele uma trajetória especial, tendo deslocado-se rapidamente de uma posição periférica (de alheamento e estranhamento) a uma posição nuclear (de participação ativa). Nessa passagem, deixou algo de si com o coletivo e, na outra mão, incorporou valores, visões de mundo presentes naquele ambiente.

A perspectiva que adotamos busca realçar o lugar do sujeito, o seu diálogo com o que se apresentam como realidades, a construção discursiva que informa suas práticas, suas escolhas, alianças, identidades e diferenças, sua experiência. ${ }^{27}$ Tomamos a experiência sindical do ABC como algo, ao mesmo tempo, dotado de certa consistência (porque encerra uma tradição, uma cultura, que influencia de determinada maneira os acontecimentos, sugerindo continuidades) e de certa fluidez (porque dotado de uma dinâmica

\footnotetext{
${ }^{27}$ Não se trata, portanto, de desenvolver uma análise de possibilidades objetivamente dadas, detendo-se em elementos supostamente determinantes da prática sindical e das alternativas que a ela se colocam. Procuramos nos apoiar no conceito de experiencia, no sentido empregado por Thompson (1981), o que exige uma abordagem do diálogo estabelecido, em uma perspectiva histórica, entre os sujeitos nela envolvidos e as evidências e estruturas que configuram a materialidade que os impregna.
} 
flexível, ora ampliando-se, ora retraindo-se, e porque retoma a cada vez suas próprias referências, memória, tradição, e as refaz em novas bases, sugerindo descontinuidades e até rupturas).

\section{O movimento de resistência contra as demissões ${ }^{28}$}

O anúncio, pela Ford de São Bernardo, das 2800 demissões, no dia 18 de dezembro de 1998, pegou a todos de surpresa. O Sindicato e a Comissão de Fábrica se posicionaram contra a medida, exigindo abertura de negociações. Uma assembléia com demitidos e não demitidos foi convocada para o dia 4 de janeiro, no pátio da fábrica, quando estava prevista a volta do recesso de final de ano. A estratégia era a de que todos vestissem seus macacões e assumissem seus postos de trabalho, pondo a fábrica para funcionar. Para as lideranças, se os demitidos começassem a trabalhar, as demissões seriam anuladas. ${ }^{29}$ Ao invés da estratégia habitual da greve, a opção foi por resistir às demissões se dispondo ao trabalho. A expressiva participação na primeira assembléia, e nas que se seguiram por meses, deu o tom da capacidade de resistência a que estavam dispostos os trabalhadores. A pronta reação da empresa, adiando o retorno ao trabalho para o dia seguinte, visando esvaziar a reação que se esboçava e, em seguida, a resposta dos trabalhadores, realizando uma plenária na sede do Sindicato, indicavam o jogo de forças, em lances diários, que se seguiria a partir dali. No dia seguinte, em nova assembléia na porta da empresa, os trabalhadores repetem a estratégia de situarem-se nos seus postos de trabalho e aguardarem instruções dos supervisores, que não se pronunciam. As máquinas da estamparia são acionadas à revelia da empresa, que adia mais uma vez a volta ao trabalho para o dia seguinte. Daí por diante os trabalhadores da Ford, o Sindicato e seus aliados, a empresa e o governo federal, sob de condições dadas e estratégias próprias, lançam-se em sucessivas movimentações, buscando influir no desfecho dos acontecimentos.

Da parte dos trabalhadores e do Sindicato, o movimento ganhou uma repercussão e uma dimensão inesperadas. Os trabalhadores mantiveram-se mobilizados, realizando assembléias diárias, determinados a resistir às demissões, não aceitando as investidas da empresa, que ora ameaçava com outras punições ora acenava com novas vantagens indenizatórias para os demitidos. ${ }^{30}$ Os líderes do movimento, desde o primeiro momento e ao longo do

\footnotetext{
${ }^{28}$ Para uma reconstituição detalhada do movimento, desde o seu início até o seu desfecho final em meados de 2000, ver Véras (2002b).

${ }^{29}$ Diário do Grande $A B C$ (DGABC), 05/01/99.

${ }^{30}$ João Ferreira Passos, o Bagaço, diretor do Sindicato, traduz o espírito do movimento: "Nós avisamos que, a cada ação da Ford, promoveríamos uma reação" (DGABC, 18/01/99).
} 
seu curso, procuraram preparar os envolvidos para o caráter de longa duração daquela luta, dadas as condições desfavoráveis em que se situava. ${ }^{31}$ Entretanto, o Sindicato e a empresa bem o sabiam, o sucesso do movimento dependeria da unidade de ação a ser articulada entre demitidos e não demitidos. A estratégia adotada pelo Sindicato foi a de procurar sensibilizá-los, indistintamente, sob o pano de fundo do problema geral do desemprego, quanto aos riscos que a todos envolviam. ${ }^{32} \mathrm{O}$ medo da demissão, normalmente utilizado pelas empresas para desmobilizar os trabalhadores, foi trabalhado aqui como um aspecto da estratégia do Sindicato no sentido inverso. Ganhou destaque a participação das mulheres e familiares dos demitidos. De início, foi constituído, com a participação de Luiza, o Comitê de Mulheres dos Demitidos, que buscaram articular ações como a realização da Ceia de Natal Simbólica, no dia 13 de janeiro. ${ }^{33}$ Foram iniciativas assim que contribuíram para realçar o caráter dramático do episódio, imprimindo-lhe um sentido de questão social ${ }^{34}$, para além de uma questão de mercado (sentido que o discurso neoliberal tenta impor). Outro destaque foi a dimensão da solidariedade alcançada pelo movimento, através dos demais metalúrgicos da região, dos demais setores sindicais ligados à CUT e de outros segmentos da sociedade. ${ }^{35}$ A existência de administrações municipais e de

\footnotetext{
31 Ver, por exemplo, editorial da Tribuna Metalúrgica - TM (04/01/99), jornal diário do SMABC, e depoimento de Vicentinho (DGABC, 05/01/99), no início, e TM (04/01/99) e depoimento de Luiz Marinho (Diário Popular, 04/02/99), no meio do processo.

32 "Lutar contra as demissões anunciadas pela Ford é compromisso de todos os trabalhadores na empresa, e não só dos que receberam a carta e demissão. Ninguém, horista ou mensalista, sabe qual será seu futuro aqui, por isso nossa unidade é mais importante que nunca” (TM, 04/01/99).

33 "A idéia é mostrar que a luta não é só dos 2,8 mil trabalhadores demitidos, mas de 2,8 mil famílias" (uma das mulheres envolvidas, $D G A B C, 11 / 01 / 99$ ).

34 Segundo Castel (1998: 495-496), "Ou não há, como pretendia Gambetta, senão 'problemas sociais' particulares, uma pluralidade de dificuldades a enfrentar uma a uma, ou há uma questão social e é a questão do estatuto do salariado, porque chegou a estruturar nossa formação social quase inteiramente. O salariado acampou durante muito tempo às margens da sociedade; depois aí se instalou, permanecendo subordinado; enfim, se difundiu até envolvê-la completamente para impor sua marca por toda parte. Mas é exatamente no momento em que os atributos vinculados ao trabalho para caracterizar o status que situa e classifica um indivíduo na sociedade pareciam ter-se imposto definitivamente, em detrimento dos outros suportes da identidade, como o pertencimento familiar ou a inscrição numa comunidade concreta, que essa centralidade do trabalho é brutalmente recolocada em questão. Teremos chegado a uma quarta etapa de uma história antropológica da condição de assalariado, etapa em que sua odisséia se transforma em drama?”.

35 "O maior trunfo dos trabalhadores está sendo a solidariedade, nascida aqui dentro e que ganhou dimensão nacional. Entidades e movimentos que nos apoiam enviaram alimentos e dinheiro para sustentar nossa luta pelo emprego. A solidariedade é a grande arma dos trabalhadores para enfrentar este novo modelo econômico que toma conta do mundo. Você já percebeu que a globalização exige uma dose alta de individualismo? E você, paga esse preço? (...) Um dos méritos do nosso movimento foi justamente remar contra essa maré individualista, despertando a solidariedade e fazendo dela nossa arma pelo emprego" (Jornal da Comissão de Fábrica da Ford, março de 1999).
} 
parlamentares identificados com o sindicalismo do ABC, assim como o espaço de articulação da sociedade civil representado pela Câmara Regional do $\mathrm{ABC}^{36}$ e o momento especial de articulação dos governadores de oposição, que discutiam alternativas às políticas do governo federal ${ }^{37}$, foram também fatores importantes para a afirmação e projeção do movimento. Entre assembléias com os trabalhadores da Ford, atos públicos de solidariedade, reuniões com políticos de oposição, audiências com representantes do governo federal ${ }^{38}$, encontros de negociação com dirigentes da empresa, imagens e argumentos veiculados pela mídia, o movimento vai articulando um discurso que se sustenta pelo menos nos seguintes elementos: uma exigência básica - a revogação das demissões - e a abertura para a negociação de alternativas. ${ }^{39}$ De outro lado, denuncia a responsabilidade política do governo federal para com a problemática do desemprego ${ }^{40}$ e propõe políticas públicas para o setor automobilístico, visando a reversão do quadro de retração da produção e de fechamento de postos de trabalho nesse setor, ${ }^{41}$ de modo a obter condições mais favoráveis na negociação do caso específico dos demitidos da Ford. Nesse momento combinam-se elementos da tradição conflitiva (exigência e denúncia) com outros que passaram a ser mais valorizados na experiência sindical dos metalúrgicos do $\mathrm{ABC}$, sobretudo nos anos 90 (proposição e negociação). ${ }^{42}$ Note-se, porém, que o principal objetivo do movimento era o de trazer a empresa e o

${ }^{36}$ Fórum público constituído por entidades da sociedade civil e setores do executivo e legislativo locais e estadual, visando a promoção de uma perspectiva comum de desenvolvimento para a região. A esse respeito, ver, por exemplo, Câmara do ABC (1999), Leite (2000) e Daniel (2001).

37 "Governadores endividados e temerosos da queda de arrecadação que terão com tamanha contração econômica e desemprego começam a apoiar as idéias de Marinho, que vão além do caso dos demitidos: a redução de juros, alguma proteção para a indústria nacional, a criação de projetos setoriais de desenvolvimento, como por exemplo o incentivo à renovação da frota de automóveis no Brasil" (O Estado de São Paulo - ESP, 10/01/99).

${ }_{38}$ Ministros, o presidente do Senado, Antônio Carlos Magalhães, e o próprio Fernando Henrique Cardoso.

39 Ver carta enviada pelo Sindicato para a diretoria da Ford (TM, 05/01/99).

40 "O governo federal e o antigo governo do Rio Grande do Sul deram R \$ 1,5 bilhão para a Ford montar uma fábrica no Estado, que vai gerar pouco mais de 700 empregos com salários achatados. Enquanto isso, a Ford demite 2.800 trabalhadores no ABC. Isto é, além de promover uma política econômica desastrosa, onde os juros altos impedem o crescimento e aumentam as demissões - como é o caso da Ford -, o governo FHC mantém uma política industrial onde o governo patrocina grandes empresas sem exigir nenhum compromisso social" (TM, 04/01/99).

${ }^{41}$ Através, por exemplo, da proposta do Programa de Renovação de Frotas $($ SMABC, 1998) e do Plano Emergencial, lançados no final do ano anterior.

${ }^{42}$ Para abordagens diferenciadas entre si a esse respeito, ver, por exemplo, Antunes (1997), Blass (1998), Rodrigues (1999) e Boito Jr. (1999). 
governo para o campo da negociação. São esses, sobretudo, que não se recusam a ela. ${ }^{43}$

A Ford optou pelas demissões sem negociar com os trabalhadores e o Sindicato. As justificou através de um argumento técnico: frente a uma situação de crise internacional e saturação do mercado interno, não se colocavam alternativas. ${ }^{44}$ A estratégia da empresa, apesar das dimensões de sua decisão (2,8 mil dispensas anunciadas de uma única vez), foi a de procurar dar um tratamento individualizado aos demitidos e um caráter estritamente técnica ao caso: as anuncia através de cartas pessoais; o faz durante as férias coletivas; procura driblar a intermediação sindical (que é legal, no que se refere à homologação das demissões) ${ }^{45}$; evita dar publicidade ao caso ${ }^{46}$. Uma vez esboçado um quadro de resistência, por parte dos trabalhadores, a empresa procura atuar no sentido de separar demitidos e não demitidos e, com isso, atingir a estratégia sindical. Tenta, sem sucesso, impedir que os demitidos entrem na fábrica. Impede que a fábrica funcione com os demitidos presentes. Lança mão por diversas vezes do recurso da licença remunerada. Só no mês de janeiro o fez por duas vezes. E, ao final, admite: "Não estamos conseguindo produzir pela presença dos demitidos na fábrica" (DGABC, 15/01/99). A Ford tenta dissuadir os trabalhadores propondo, no dia 22 de janeiro, uma ampliação nos benefícios para os demitidos. Era um sinal de que a empresa reconhecia a resistência dos trabalhadores, mas ainda não admitia negociar com o Sindicato. Certamente contava com os efeitos da crise que, na ocasião, se abatia sobre a economia brasileira, com particular repercussão sobre os empregos no setor automotivo ${ }^{47}$. Mas, ao invés do

\footnotetext{
43 "O que a destruição do público opera em relação às classes dominadas, como o exemplo da câmara setorial do setor automotivo nos mostra, é a destruição de sua política, o roubo da fala, sua exclusão do discurso reivindicativo e, no limite, sua destruição como classe; seu retrocesso ao estado de mercadoria, que é o objetivo neoliberal" (Oliveira, 1999: 79).

44 "A indústria automobilística brasileira está estruturada para um mercado acima de 2 milhões de veículos, enquanto a realidade atual projeta uma produção de cerca de 1,3 milhão de unidades em 1999 (...) Como conseqüência, a Ford teve de reduzir a sua produção, em São Bernardo do Campo, de 1.100 carros/dia para cerca de 500 carros/dia, visando adequar-se à demanda" (Informe publicitário assinado pela Ford, veiculado nos principais jornais do país em 18 de janeiro de 1999). ${ }^{45}$ A empresa disponibiliza as verbas das indenizações em agências bancárias e chama os demitidos a assinarem a rescisão e sacarem o dinheiro. O Sindicato denuncia: "Esse golpe de depositar as verbas rescisórias foi baixo" (Rafael Marques, coordenador da Comissão de Fábrica da Ford, $D G A B C, 17 / 01 / 99)$.

${ }^{46}$ Após o anúncio, que não podia deixar de ser comunicado publicamente, a Ford só veio se pronunciar oficialmente no dia 18 de janeiro, quanto fez circular na imprensa um informe publicitário, procurando se justificar, já em um momento em que o caso havia ganhado repercussão nacional.

${ }^{47}$ Que teria fechado cerca de 10 mil postos de trabalho durante 98 (Folba de São Paulo - FSP, 26/12/98).
} 
desgaste do movimento de resistência às demissões, ocorreu o contrário, o desgaste da empresa junto à opinião pública. Além do mais, esta se viu diante de um impasse: entre a necessidade de impedir o acesso dos demitidos, ao custo (crescente) de ter que manter a produção desativada, e o risco de reativar a produção e, assim, ter que ceder à estratégia do Sindicato de conclamar todos ao trabalho, como forma de não reconhecimento das demissões.

Da parte do governo federal, o que prevaleceu foi a omissão em relação ao caso. O discurso oficial insistia na idéia de que não caberia ao governo intervir, visto que se tratava de assunto para "negociação direta entre metalúrgicos e a empresa”, ${ }^{48} \mathrm{em}$ um jogo próprio das dinâmicas do mercado. ${ }^{49}$

A mobilização se manteve apesar das pressões da empresa e das omissões do poder público. Assembléias diárias na porta da fábrica e manifestações pelas ruas do $\mathrm{ABC}$, envolvendo trabalhadores de outras empresas e outros segmentos da sociedade, foram a marca do movimento. No dia 30 de janeiro, ao fim de duas semanas de licença remunerada, mais uma vez lá estavam todos em nova assembléia na porta da empresa. No dia seguinte, a Ford recua nas demissões, se dispõe a negociar com o Sindicato e apresenta uma proposta que incluía abertura de um Plano de Demissão Voluntária (PDV) até o dia 12 do mês, a realização de um balanço das adesões no dia 18 e a retomada das negociações no dia 22. O setor de Peças e Acessórios - PA, que incluía 250 trabalhadores na lista dos demitidos, ficou de fora da proposta. Dos 2800 demitidos, 2100 ficariam em licença remunerada (cerca de 700 deles já haviam feito a rescisão). Os salários de janeiro seriam pagos em duas parcelas e os convênios médicos seriam mantidos até 30 de abril ou o direito a um abono de $\mathrm{R} \$ 900$. Numa assembléia com cerca de 6 mil pessoas, realizada no dia 3 de fevereiro, os trabalhadores aprovam a proposta da Ford. A fábrica de São Bernardo voltou a produzir, depois de 48 dias

${ }^{48}$ Francisco Dornelles, Ministro do Trabalho (ESP, 10/01/99). Em outras entrevistas, chegou a apelar para que as empresas olhassem o "lado social", mas sempre reafirmando que o governo não tinha "base legal" para intervir (DGABC, 12/01/99 e 15/01/99). Esse foi o mesmo tom de entrevistas de Celso Lafer, então ministro do Desenvolvimento $(D G A B C, 11 / 01 / 99)$ e do próprio FHC (DGABC, 11/01/99).

${ }_{49}$ Flagrante a esse respeito foi a declaração de FHC, dada no momento em que a Ford ameaçava fechar sua unidade no Ipiranga e em que o governo federal e o governo da Bahia destinavam incentivos fiscais e empréstimos a juros especiais para a implantação de uma nova unidade da empresa nesse Estado. Diante da pressão dos trabalhadores para que o governo tentasse impedir o fechamento da planta, o presidente declarou: "Eu não tenho como gerir uma decisão da Ford, não é meu papel. Isso é outra questão (...) Eu não sou da Ford. Não tenho nada a ver com a Ford, não sei o que eles vão fazer (...) Também respeito totalmente os operários da Ford, acho que eles têm de lutar pelo emprego deles e têm o meu apoio na luta pelo emprego, sempre (...) É uma decisão da Ford. Eu não tenho como ingerir na decisão da Ford... Foi para a Bahia porque quis, não porque eu tivesse induzido" (FSP, 23/07/99). 
parada. Foi a primeira vez que uma montadora fez cortes em massa e voltou atrás. Aquele desfecho foi saudado como uma grande vitória pelas lideranças sindicais e políticas. ${ }^{50}$

No dia 18 de fevereiro, a Ford, a Comissão de Fábrica e o Sindicato constatam 551 adesões ao PDV. A empresa reage, insatisfeita. Nova rodada de negociação é marcada para o dia 22. No dia 25, novo acordo é realizado: os 1543 ex-demitidos teriam seus contratos suspensos, sem rescisão (nos termos da Medida Provisória 1.726/98, que regulamentou a suspensão temporária dos contratos); receberiam por cinco meses o salário líquido integral ( $\mathrm{R} \$ 243$ fornecida pelo Seguro Desemprego e o restante complementado pela empresa); poderiam freqüentar um curso de qualificação profissional no Senai ${ }^{51}$; mas não teriam direito ao desconto previdenciário, ao depósito do FGTS $^{52}$, nem às parcelas proporcionais das férias e do 13. ${ }^{\circ}$ salário. A empresa se comprometeria, ainda, a reintegrar imediatamente cerca de 300 trabalhadores com estabilidade. Dali em diante novos PDV são lançados pela empresa, os contratos se mantêm em suspenso, com parcelas de trabalhadores sendo reintegrados, até que em agosto de 2000 cerca de 700 trabalhadores (últimos do grupo de 2,8 mil) negociaram um pacote de demissões com a empresa.

\section{Reflexões finais}

De imediato, os resultados obtidos pelo movimento produziram uma sensação de euforia. ${ }^{53}$ Além de ter conseguido reverter, em caráter inédito, as demissões da Ford, o movimento conquistou um acordo vantajoso, mesmo para o elevado padrão do ABC. O contraste é ainda mais flagrante se, como Mattos (1998), o comparamos com os acordos celebrados pelos sindicatos

\footnotetext{
${ }^{50}$ Luiz Marinho chegou a confessar: "Desde o início achava difícil, não impossível, conseguir o que conseguimos" (TM, 04/02/99). Lula não economizou elogios: "Na história da luta contra o desemprego, não tem precedente a Ford voltar atrás. Foi uma grande vitória” (Diário Popular - DP, 04/02/99).

${ }^{51}$ Serviço Nacional da Indústria (órgão voltado à qualificação profissional, administrado por entidades empresariais).

${ }^{52}$ Fundo de Garantia por Tempo de Serviço (criado no início do regime militar, para substituir o direito de estabilidade no emprego após 10 anos de vínculo).

53 "No mínimo os companheiros da Ford mostraram ao País que os trabalhadores ainda estão vivos, apesar do recuo das lutas sociais provocado pela recessão. Mostraram que, apesar da hegemonia neoliberal sobre toda a sociedade, ainda é permitido lutar. E, mais importante, ainda é possível obter sucesso em novas lutas, pelo menos em cima de objetivos imediatos e parciais, como foi o caso da suspensão das 2.800 demissões da Ford.”(Luiz Marinho, Unidade Metalúrgica, março de 1999); "Não dá para explicar a sensação. Nem se eu pegasse o dicionário, eu explicaria o que estou sentido. Abracei uma causa. Renunciei a tudo, dormi duas horas por dia, e hoje a gente está vendo o resultado daquilo que a gente fez" (Sônia Gonçalves, esposa de um dos ex-demitidos, Diário Popular, 04/02/99).
} 
ligados à Força Sindical. O diferencial se encontra não só nos seus termos, mas também no que se refere ao modo como têm sido conduzidas as negociações. ${ }^{54}$ Entretanto, ainda no plano do balanço dos resultados imediatos, não parece ocioso se perguntar se a empresa não estaria atingindo os seus objetivos últimos, que é o de promover o "enxugamento" do seu quadro de funcionários. Basta ver que do total dos 2800 inicialmente demitidos, próximo de 1300 rescisões foram efetivadas só até o final do mês de fevereiro, seja ao aceitarem a demissão, seja ao aderirem ao PDV. Mattos (1998), se referindo a uma tendência mundial, quanto aos acordos entre trabalhadores e empresas, argumenta que neles tem prevalecido uma lógica que resulta sempre em desemprego (na forma de demissões "compulsórias" ou "voluntárias”), mesmo onde o sindicalismo tem forte tradição.

Para uma abordagem mais atenta desse movimento, no entanto, sugerimos que sejam considerados outros aspectos. Poderíamos nos perguntar, por exemplo, sob que perspectiva o sindicalismo do $\mathrm{ABC}$ enfrentou o fato criado com as demissões na Ford. Em um contexto de hegemonia neoliberal, ${ }^{55} \mathrm{em}$ que medida a experiência em questão se colocou em uma perspectiva de resistência? Blass (1998: 81) chama a atenção para o fato de que, também no $\mathrm{ABC}$, as lideranças sindicais e os trabalhadores

são conclamados a negociar, mas não podem perder de vista as tendências do mercado e a defesa do emprego. Por isso, vêem-se obrigados a se colocar na perspectiva da empresa para preservar o emprego. Nesse jogo de poder, são chamados a assumir responsabilidades sociais, evidenciando o desequilíbrio na correlação de forças entre trabalhadores, sindicatos e empresas transnacionais e o modo de inserção de cada país na divisão internacional da produção e do trabalho.

Foi o que constatamos por ocasião do primeiro acordo a respeito das demissões da Ford, no dia 4 de fevereiro, o qual implicou em um compromisso entre Sindicato, Comissão de Fábrica e a Ford, no sentido de pensa-

\footnotetext{
54 "A luta fez a diferença. A união dos demitidos com os não-demitidos e a solidariedade trouxeram a conquista. O desfecho do movimento de resistência abre uma grande janela e um bom horizonte para nós trabalhadores na Ford do Ipiranga, e para os companheiros de Taubaté" (Paulão, da Comissão de Fábrica da Ford Ipiranga, na TM, 04/02/99).

55 Para Oliveira (1998: 203), o conceito de hegemonia não daria mais conta do atual projeto dominante: "apesar de que a aparência seja de uma hegemonia finalmente lograda, após o longo período de violentas transformações e de pesados ajustes no interior do bloco dominante, que sempre se renovou, diga-se de passagem, o conceito perde eficácia porque o processo em curso não é integrador. O totalitarismo, apesar de seu claro inacabamento, parece mais produtivo teoricamente. Ele se refere a um processo de destruição do campo de significados comuns a dominantes e dominados, e seu sonho é o apartheid total".
} 
rem o "futuro da empresa". ${ }^{56}$ Mas eis que as propostas defendidas por cada parte os distanciam novamente: enquanto a empresa prioriza a redução do absenteísmo, uma maior flexibilização da jornada, a revisão da estrutura salarial dos horistas e a terceirização de novos setores, o Sindicato e a Comissão de Fábrica defendem a garantia de emprego, a desterceirização de alguns setores e a garantia da ida de um novo produto para a unidade de São Bernardo. O desafio de compor uma estratégia consistente exige do Sindicato um nível de formulação complexo, que implica em admitir alguns elementos do discurso empresarial, ao mesmo tempo fazendo-o de modo a diferenciar-se dele e a contestá-lo. No editorial da TM, do dia 4 de fevereiro, intitulado sugestivamente de "É preciso dizer não ao desemprego e apresentar propostas”, encontra-se uma síntese dessa composição contraditória:

O movimento dos metalúrgicos na Ford marca uma mudança na luta dos trabalhadores do País. Ninguém deve mais aceitar a lógica do patrão, de demitir para superar a crise econômica. Esse raciocínio leva o Brasil para o buraco, e toda a sociedade paga um alto preço: mais desemprego acarreta menos poder de compra, que faz cair as vendas, com menos produção e mais demissão. É um círculo vicioso. Esperamos que a partir de agora tudo isso mude, com os trabalhadores dizendo não às demissões e apresentando alternativas. Há tempos nosso Sindicato busca novas saídas para a superação de crises. O banco de horas e a jornada flexível é uma proposta que continua evitando demissões. O criativo acordo com a Volks abriu imensas alternativas ao desemprego. E a Câmara Setorial em 1992/1993 reativou a indústria automobilística, com reflexos em toda a economia brasileira. E mais, a luta contra o trabalho infantil, o movimento de alfabetização - Mova, entre muitos outros gestos de nossa categoria, mostram que acreditamos nas possibilidades de transformar o Brasil num País justo e que ofereça melhor qualidade de vida a todos nós. Neste momento estão com o governo federal duas idéias nossas para a retomada da produção: o Plano Nacional de Renovação da Frota e o Plano Emergencial.

A luta pela preservação dos postos de trabalho, para resistir à precarização dos contratos de trabalho e para garantir a si próprio um espaço nesse novo contexto tem levado o Sindicato a se projetar para além das negociações diretas com as empresas. Supomos que isso ocorre em parte por haver um reconhecimento, no meio sindical, de que tais desafios não se resolvem nesse âmbito restrito, exigem uma solução pública e, por outra parte, para desvencilhar-se de uma dinâmica na qual se encontra em uma

\footnotetext{
56 "Essa discussão é muito importante e fundamental para nossas vidas. Por isso, os trabalhadores precisam participar ativamente do processo que está começando" (Jornal da Comissão, março de 1999).
} 
condição de refém das iniciativas das empresas. ${ }^{57} \mathrm{O}$ objetivo é o de procurar influir na formulação e gestão de políticas públicas que possam concorrer para reverter o quadro adverso. É o que passou a ser conhecida como uma linha de ação de caráter propositivo.

Diríamos que convivem, nessa estratégia (sob tensões), uma certa capacidade de resistência e um certo nível de aderência frente aos apelos/ chantagens do discurso empresarial. Nos perguntamos se seria possível experienciar-se a primeira sem incorporar em alguma medida elementos da segunda. Talvez pudéssemos questionar se a ênfase tem recaído mais no primeiro ou no segundo aspecto. No caso do sindicalismo do ABC, ao se encontrar lastreado em uma tradição política fortemente auto-referida, prevalece o objetivo de atrair a contraparte para o campo da negociação ${ }^{58}$, o que revela também o seu caráter defensivo.

Daquilo que pudemos apreender, a partir das considerações acima desenvolvidas, um movimento assim, que se debate com uma dinâmica que exige total aderência de toda a sociedade, ao se lançar em busca de alternativas, do modo como o fez, não poderia deixar de revelar um sentido profundo de movimento de resistência. Entretanto, até onde conseguiu se afirmar nessa perspectiva?

Um dado importante a considerar é que o movimento sugeriu uma dinâmica contrária à lógica privatista, nuclear no discurso hegemônico, ao se impor como um acontecimento público ${ }^{59}$. A publicização do movimento resultou de uma combinação de elementos, tais como: a necessidade, da parte deste, em buscar apoio junto a outros segmentos da sociedade e à opinião pública em geral; ${ }^{60}$ o caráter dramático da questão do desemprego;

\footnotetext{
$57 \mathrm{O}$ tom da fala de um diretor da Ford, após o anúncio da possibilidade de 700 demissões na sua unidade do Ipiranga, é ilustrativo disso: "Acordos como o da Volks não cabem para nós. Nossa produção caiu de 220 caminhões/dia para 130 e, por isso, teremos que proteger nossos custos. Resta para os sindicatos a criatividade" (Jornal da Tarde, 14/01/99, grifo nosso).

${ }^{58}$ Como bem ilustra os termos da carta enviada pelo Sindicato à Ford, logo após o anúncio das demissões: "Lamentamos que medidas de impacto tão elevado sejam tomadas sem que tenha havido a mínima tentativa de um processo de negociação. Este Sindicato, que sempre soube buscar alternativas e tem dado provas concretas nesse sentido, exige a suspensão das demissões e a abertura imediata de negociações, visando soluções menos traumáticas para os trabalhadores, para a saúde da própria empresa, para a realidade social da região e até mesmo para a economia brasileira como um todo" (TM, 05/01/99).

59 No sentido atribuído por Arendt (1999).

${ }^{60}$ Para se ter uma idéia desse esforço, segundo O ESP (10/01/99), "O presidente do Sindicato dos Metalúrgicos do ABC, Luiz Marinho, não consegue mais esconder o cansaço. Todos os dias para ele começam às 5 horas da manhã, quando vai liderar assembléias na Ford, para em seguida decidir se enfrenta uma viagem a outros Estados ou o carregado trânsito entre São Bernardo do Campo e São Paulo, sempre em busca de apoios políticos importantes. Tem dado mais de 30 entrevistas por dia e negociado, formal ou informalmente, com a direção da empresa”.
} 
o sentido simbólico, de resistência, que foi adquirindo para os setores que se colocam de alguma maneira em uma perspectiva de oposição às forças governamentais. As audiências e reuniões públicas e a repercussão que obteve na mídia foram fundamentais para dar visibilidade ao movimento, arregimentar-lhe um amplo apoio e forçar uma releitura pública da problemática do desemprego, evidenciando este como uma questão de natureza social (enquanto um problema que diz respeito ao conjunto da sociedade) e política (cuja solução deve ser pública e amplamente debatida pela sociedade), para além de um sentido essencialmente contábil, mercadológico, técnico, como procura impor o discurso hegemônico. A politização da questão do desemprego implica na possibilidade da sua solução, dada pela sociedade e não pelo mercado, comportar várias abordagens. Nesses termos o movimento pressionou o governo e a empresa para que se dispusessem a discutir alternativas. O próprio núcleo do discurso hegemônico estava, assim, sendo tensionado, na medida em que se estrutura na intolerância frente a quaisquer formas de manifestação de dissenso ${ }^{61}$. O caráter contestatório do movimento evidenciou-se no momento mesmo em que emergiu como algo mais que uma negociação privada entre trabalhadores e empresa, suscitando a presença do Estado e lançando-se à mobilização dos trabalhadores e da sociedade, imprimindo-lhe um sentido público e político. ${ }^{62}$

O movimento inscreveu-se em um contexto tal, que lhe propiciou certas potencialidades e limites. Projetou-se como um movimento de contestação a respeito do caráter natural e inevitável das necessidades do mercado, mostrando que há espaço para a resistência e para alternativas. Articulou-se como uma ação coletiva e onde o exercício da solidariedade esteve fortemente presente, em uma contraposição clara às práticas individualistas, tão em voga em tempos de neoliberalismo. ${ }^{63}$ Evidenciou a dimensão

\footnotetext{
${ }^{61}$ Para Oliveira (1998: 368), vivemos um momento de "desuniversalização da dominação, que portanto redefine-se como apenas dominação, des-democratiza e transmuta-se em totalitarismo", marcado pela tendência "da impossibilidade do dissenso, da alternativa, do seqüestro do discurso e da fala contestatória, da anulação da política". Com Rancière (1996: 220), temos que dissenso "É a divisão do núcleo mesmo do mundo sensível que institui a política e sua racionalidade própria", acrescentando: "a racionalidade da política é a de um mundo comum instituído, tornado comum, pela própria divisão".

62 "A luta dos companheiros da Ford pela retomada de seus empregos é de todos nós. É uma luta contra a política de desemprego do governo. Ela é a vitrine da nossa insatisfação, é a resistência contra a fome, a miséria, a privatização das nossas estatais, a quebradeira das nossas indústrias" (Jornal da CUT/SP, janeiro de 1999); "Do ponto de vista simbólico, o retorno dos trabalhadores da Ford mostrou para a população de todo o País que é possível quebrar o discurso hegemônico neoliberal, de necessidade de 'enxugamento da máquina', 'reestruturação', 'reengenharia', 'custo do mercado globalizado' - que descarta pessoas como máquinas antigas e obsoletas e passou a dar vida e expressão aos índices de desemprego" (Célia Regina, DP, 03/02/99).

${ }^{63}$ Que Beynon (1997) designa por "ascensão do individualismo" e "queda da ética coletiva".
} 
social e pública de questões como o desemprego. Flagrou o significado político da omissão do governo e o seu esforço despolitizante quanto à problemática social. Ensaiou o dissenso como uma possibilidade. Forçou o alargamento do possível. ${ }^{64}$ Sinalizou em alguma medida a reemergência da política. Ao mesmo tempo, situações como a que foi abordada aqui ilustram bem as dificuldades e dilemas atuais dos processos de publicização dos movimentos sociais, frente ao forte movimento de privatização da sociedade em amplos sentidos. ${ }^{65}$

O sindicalismo metalúrgico do $\mathrm{ABC}$, como parte destacada do sindicalismo CUT, procura movimentar-se em várias direções, de maneira a enfrentar as adversidades de toda ordem e sair da posição defensiva: organiza a resistência coletiva às demissões (como no caso da Ford); procura poupar postos de trabalho com iniciativas de "reestruturação negociada"; lança-se na construção de um contrato coletivo nacionalmente articulado e de um sindicato nacional, para enfrentar a estratégia de descentralização das empresas; ${ }^{66}$ articula propostas de políticas públicas setoriais, visando reaquecer atividade industrial do setor (como ocorreu com o programa de renovação de frotas); empreende diversas iniciativas visando articular compromissos públicos de diversos atores com uma concepção social e sustentável de desenvolvimento, particularmente no âmbito regional ${ }^{67}$.

Resta saber se, com isso, será capaz de ir além e reafirmar-se como um sujeito social e político influente no cenário nacional. Tal desfecho está em aberto.

\section{Referências Bibliográficas}

Antunes, Ricardo (1997), "Trabalho, reestruturação produtiva e algumas repercussões no sindicalismo brasileiro", in R. Antunes (org.), Neoliberalismo, trabalho e sindicatos: Reestruturação no Brasil e na Inglaterra. São Paulo: Boitempo Editorial, 71-84. Arbix, Glauco (1996), Uma aposta no futuro: Os primeiros anos da Câmara Setorial da Indústria Automobilística. São Paulo: Scritta.

\footnotetext{
${ }^{64} \mathrm{Na}$ fala de Luiz Marinho: "A Ford teve de voltar atrás. A partir daí, tudo é possível” (DP, 04/02/99) e de Lula: "Essa peãozada entende o simbolismo do que aconteceu aqui hoje. Ela viu, pela primeira vez, que é possível não aceitar o desemprego como fato consumado" (Unidade Metalúrgica, março de 1999).

${ }^{65}$ Para Oliveira (1998) prevalece a "privatização do público, a destituição da fala e a anulação da política".

${ }_{66}$ Ver a respeito Véras (2001).

${ }^{67}$ Tais como: a Câmara Regional do ABC, o Fórum da Cidadania, a Central de Trabalho e Renda, o Programa Integrar (qualificação profissional), o Mova (Movimento de Alfabetização), a Unisol (central de cooperativas), entre outras. Todas implicando em novas relações com a sociedade e, conseqüentemente, com a esfera pública.
} 
Arbix, Glauco (2001), "Guerra fiscal, espaço público e indústria automobilística no Brasil”, in Roberto Véras (org.), Ação sindical no espaço local. São Paulo: Escola Sindical CUT, 137-156.

Arbix, Glauco; Zilbovicius, Mauro (orgs.) (1997), De JK a FHC - A reinvenção dos carros. São Paulo: Scritta.

Arendt, Hannah (1999), A condição bumana. Rio de Janeiro: Forense Universitária, 9. ${ }^{a}$ edição.

Beynon, Huw (1997), “As práticas do trabalho em mutação”, in R. Antunes (org.), Neoliberalismo, trabalho e sindicatos: Reestruturação no Brasil e na Inglaterra. São Paulo: Boitempo Editorial, 9-38.

Blass, Leila (1998), “Alcance e limites da reestruturação negociada”, São Paulo em Perspectiva, 12(1), 77-84.

Blass, Leila (2001), De volta ao futuro: O discurso empresarial e sindical no fim da Autolatina. São Paulo: Educ.

Boito Jr., Armando (1991), "Reforma e persistência da estrutura sindical", in A. Boito Jr. (org.), O sindicalismo brasileiro nos anos 80. Rio de Janeiro: Paz e Terra.

Boito Jr., Armando (1999), Política neoliberal e sindicalimso no Brasil. São Paulo: Xamã, 43-92.

Câmara do ABC (1999), A região encontra soluções.

Cardoso, Adalberto M.; Comin, A. (1995), "Câmaras setoriais, modernização produtiva e democratização nas relações de trabalho: A experiência do setor automobilístico no Brasil", in Nadya Castro (org.), 387-425.

Castel, Robert (1998), As metamorfoses da questão social: Uma crônica do salário. Petrópolis: Editora Vozes.

Castro, Nadya Araújo de (org.) (1995), A Máquina e o Equilibrista - Inovação na Indústria Automobilística Brasileira. São Paulo: Paz e Terra.

Castro, S. (2000), "Movimento sindical no Mercosul: Trajetória e perspectiva de ação", in J. Lorenzetti; O. Faccio (orgs.), O sindicalismo na Europa, Mercosul e Nafta. São Paulo: LTr, 103-135.

CNM/DIEESE (1998), Diagnóstico do Complexo Metal-Mecânico. São Paulo.

Daniel, Celso (2001), "Uma experiência de desenvolvimento econômico local: A Câmara Regional do Grande ABC”, in Roberto Véras (org.), Ação sindical no espaço local. São Paulo: Escola Sindical CUT, 113-129.

Fiori, L. (1997), Os moedeiros falsos. Petrópolis: Editora Vozes.

Krein, J. D.; Oliveira, M. A. (1999), "Mudanças institucionais e relações de trabalho: As iniciativas do Governo FHC no período 1995-1998”, in VI Encontro Nacional de Estudos do Trabalho - Anais. São Paulo: ABET, 285-304.

Leite, M. (2000), Desenvolvimento econômico local e descentralização na América Latina: A experiência da Câmara Regional do Grande ABC no Brasil. São Paulo (mímeo). 
Mattos, M. B. (1998), Os sindicatos e o desemprego no Brasil. Trabalho apresentado na Anpocs (mímeo).

Melo, L. (2001), “Trabalhadores do Mercosul: Uni-vos!': A construção de uma voz coletiva contra-hegemônica: Quando o Dissenso é "Pôr-se de Acordo Com, a Propósito De", in Boaventura de Sousa Santos (org.), Projeto Reinvenção da Emancipação Social, Coimbra. Disponível em: <http://www.ces.fe.uc/emancipa/pt>.

O’Donnell, G. (1988), "Hiatos, instituições e perspectivas democráticas”, in O’Donnell, G.; Reis, F. W. (orgs.), Democracia no Brasil: Dilemas e perspectivas. São Paulo: Vértice, 56-82.

Oliveira, Francisco (1998), Os direitos do antivalor: A economia política da begemonia imperfeita. Petrópolis: Editora Vozes.

Oliveira, Francisco (1999), "Privatização do público, destituição da fala e anulação da política: O totalitarismo neoliberal”, in F. Oliveira; M. Paoli (orgs.), Os sentidos da democracia. São Paulo: Ed. Vozes, 55-81.

Oliveira, Francisco et al. (orgs.) (1992), “Os cavaleiros do antiapocalipse: O acordo das montadoras”. São Paulo. Projeto de Pesquisa, Cebrap (mimeo).

Oliveira, Francisco et al. (orgs.) (1993), "Quanto melhor, melhor: O acordo das montadoras", Novos Estudos Cebrap, 36, 3-7.

Paoli, M. C. (1999), “Apresentação e introdução”, in F. Oliveira; M. Paoli (orgs.), Os sentidos da democracia. São Paulo: Ed. Vozes, 7-23.

Paoli, M. C.; Telles, V. (2000), "Direitos sociais, conflitos e negociações no Brasil contemporâneo", in Alvarez et al. (orgs.), Cultura e política nos movimentos sociais latino-americanos: Novas leituras. Belo Horizonte: Editora UFMG, 103-148.

Pochmann, M. et al. (1998), "Ação sindical no Brasil: Transformações e perspectivas”, São Paulo em Perspectiva, 12(1), 104-117.

Rancière, J. (1996), “O Dissenso”, in A. Novaes (org.), A crise da razão. São Paulo: Companhia das Letras, 302-335.

Rodrigues, Iram Jácome (1999), “A trajetória do novo sindicalismo”, in Iram Jácome Rodrigues (org.), O novo sindicalismo vinte anos depois. Rio de Janeiro: Ed. Vozes; São Paulo; Educ/Unitrabalho, 73-94.

Schmitter, P. (1974), “Still a Century of Corporatism?”, in F. Pike; T. Stritch (orgs.), The New Corporatism. Notre Dame: Notre Dame University Press, 88-116.

Siqueira Neto, J. (1996), "Flexibilização, desregulamentação e o direito do trabalho no Brasil”, in C. Oliveira; J. Mattoso, Crise e trabalbo no Brasil: Modernidade ou volta ao Passado?. São Paulo: Scritta, 233-264.

SMABC (1994), Sem peças o Brasil não anda.

SMABC (1996), Globalização e setor automotivo: A visão dos trabalhadores.

SMABC (1998), Renovação e reciclagem da frota de veículos: As propostas dos metalúrgicos do $A B C$.

Thompson, E. P. (1981), A miséria da teoria ou um planetário de erros. Rio de Janeiro: Zahar Editora. 
Uriarte, O. (1995), "El futuro del derecho del trabajo y las relaciones laborales", in M. S. Castro; A. Wachendorfer (orgs), Sindicalismo latinoamericano: Entre la renovación y la resigniación. Venezuela: Nueva Sociedad; Brasil: Ildes-Fes, 47-56.

Uriarte, O. (1996), "Flexibilização e reforma trabalbista na América Latina". São Paulo: GT-RP CUT (mímeo).

Véras, Roberto (2001), “Sindicalismo metalúrgico, o 'festival de greves' e as possibilidades do Contrato Coletivo Nacional”, in Boaventura de Sousa Santos (org.), Projeto Reinvenção da Emancipação Social, Coimbra. Disponível em: <http://www.ces.fe.uc/ emancipa/pt>.

Véras, Roberto (2002a), "Sindicato cidadão: Novos rumos do sindicalismo brasileiro", Oficina do CES, 166.

Véras, Roberto (2002b), O ABC da resistência: Quando certos personagens resistem para permanecer em cena. São Bernardo do Campo: SMABC.

Weffort, F. (1973), "Origens do sindicalismo populista no Brasil: A conjuntura do após-guerra”, Estudos Cebrap, 4, 65-106.

Zapata, F. (1994), “Crise do sindicalismo na América Latina?”, Dados - Revista de Ciências Sociais, 37(1), 81-111. 